\title{
Os planos municipais de educação: entre a recentralização e as regulações locais
}

\section{The municipal plans of education: between the recentralization and local regulations}

\author{
Los planes municipales de la educación: entre la recentralización y \\ las regulaciones locales
}

\author{
JORGE MARTINS*
}

RESUMO - No contexto de um novo quadro de descentralização educativa, e tendo como objecto de reflexão os manuais de gestão educativa municipal, onde são patentes as escolhas feitas pelos autarcas relativamente aos objectivos do planeamento estratégico e aos processos de gestão educacional num determinado conjunto de municípios portugueses, este texto procura caracterizar a dialética estabelecida entre as políticas educativas nacionais e as locais e identificar os principais pontos de homogeneidade e de heterogeneidade das respectivas políticas. Conclui que os planos educativos municipais são muito influenciados pela agenda nacional e pela descentralização contratualizada que o governo apresentou aos municípios recentemente, por meio dos contratos de execução. Estes, embora não tenham sido aceites por todas as câmaras, acabaram por influenciar o municipalismo educativo, cumprindo assim o seu primordial papel regulador e recentralizador.
\end{abstract}

Palavras-chave - Municipalismo educativo. Plano municipal de educação. Regulação local. Recentralização educacional.

\begin{abstract}
In the context of a new frame on educative decentralization, and having as object of reflection municipal educative management manual's, where the choices made by the local authorities relatively to the aims of the strategical planning and to the processes of educational management in a specific set of portuguese cities are clear, this text looks for to characterize the dialectic established between the national and the local educative politics and to identify the main points of homogeneity and heterogeneity of the respective politics. We conclude that municipal educative plans are very influenced by the national agenda and by the contractualized decentralization that the government presented recently to the municipalities, through execution contracts. These, even so they have not been accepted by all the local authorities, had finished by influencing educative municipalism, thus fulfilling its primordial regulating and recentralization role.
\end{abstract}

Keywords - Educative municipalism. Educative local plan. Local regulation. Educational recentralization.

RESUMEN - En el contexto de un nuevo cuadro de la descentralización educativa, y tomando como objecto de la reflexión los manuales de la gerencia educativa municipal, donde están claras las opciones hechas por los autarcas relativamente a los objectivos del planeamiento estratégico y a los procesos de la gerencia educativa en un conjunto de ciudades portuguésas, este texto busca caracterizar la dialéctica establecida entre la política educativa nacional y las políticas locales y identificar los puntos principales de homogeneidad y heterogeneidad de la política respectiva. Nuestra conclusión es que los planes educativos municipales son muy influenciados por la agenda nacional y por la descentralización contratualizada que el gobierno portugués presentó recientemente a las ciudades, por medio de los contratos de ejecución. Éstos, sin embargo no teneren sido aceptados por todos los ejecutivos de los ayuntamientos, han acabado por influenciar el municipalismo educativo, así satisfaciendo su papel primordial de regulación y de dispositivo recentralizador.

Palabras clave - Municipalismo educativo. Plan municipal de la educación. Regulación local. Recentralización educativa.

\footnotetext{
* Doutor em Educação pela Universidade do Porto (Porto, Portugual) e Professor na Universidade do Porto (Porto, Portugual). E-mail: <jorgemartins51@ gmail.com>.
} 


\section{A PROBlemáticA - Poder Central versus Poder local no DOMÍNIO EDUCATIVO OU A DIFÍCIL DESCENTRALIZAÇÃO EDUCATIVA EM PORTUgaL}

Como uma das principais mudanças produzidas pela revolução democrática de 1974, a Constituição da República Portuguesa (CRP) reconhece explicitamente, no seu Título VIII, o Poder Local como o poder sediado nas autarquias locais.

Estas, embora restritivamente consideradas como pessoas colectivas territoriais, têm três níveis de inserção na estrutura da organização do Estado - freguesias, municípios e regiões administrativas -, e o seu poder resulta não só da representação directa de interesses próprios das respectivas populações, mas também dos meios que detêm (património e finanças locais), dos modos como se organizam (em órgãos deliberativos e executivos, democraticamente eleitos) e das competências próprias e delegadas "em harmonia com o princípio da descentralização administrativa” (CRP, art. 237º).

Do ponto de vista do cidadão, formalmente, o poder originário das autarquias locais portuguesas seria considerado tão relevante como o poder do Estado central (da administração central) se não existissem as restrições que a lei fundamental estabelece em matéria de descentralização e de tutela administrativa: por um lado, as atribuições e competências são reguladas por lei e, por outro lado, a verificação do cumprimento dessa lei cabe à tutela política e administrativa central. É nesta subalternização do poder local face ao central que radica uma parte significativa da querela jurídicopolítica em torno da autonomia, da descentralização e da desconcentração, sendo que a outra parte da querela tem a ver sobretudo com a variabilidade recorrente do financiamento das autarquias locais.

Ora, ao longo dos últimos 40 anos de democracia, a relação dos municípios com a educação tem sido marcada por um complexo processo de descentralização de poder e de transferência de competências e meios financeiros do Estado para os municípios. ${ }^{1}$

De facto, a evolução da democracia, que resultou de um corte político, económico e social muito profundo com o regime de ditadura anterior, criou nas populações condições de participação e representação nos vários níveis da sociedade (partidos, sindicatos, associações, etc.) e domínios da acção pública, nomeadamente na educação e ensino, em defesa de interesses legitimados pelo bem comum local.

Ao mesmo tempo, o modelo de administração do território - baseado no funcionamento democrático das freguesias e municípios já existentes - e as diferentes lógicas de acção municipal presentes no terreno ${ }^{2}$ tornaram o processo de descentralização educativa lento no ritmo, gradual no âmbito e ambíguo nas intenções (FERNANDES, 1994; BARROSO; PINHAL, 1996; MARTINS, 2007).

O processo foi lento porque só na década de $1980^{3}$ iniciou a sua construção normativa, foi gradual porque privilegiou sempre o domínio administrativo sobre o domínio político e financeiro e foi ambíguo porque o Estado procurou sempre soluções normativas normalizadoras que equilibrassem as vantagens e os inconvenientes da centralização e da descentralização como forma de se relegitimar e autorrecompor.

$\mathrm{Na}$ ausência de instâncias políticas e administrativas regionais eleitas, a estratégia estatal consistiu em dividir, passo a passo, tarefas e poderes de decisão entre si e os municípios. Assim, enquanto estes passaram a dispor, sobretudo no que concerne ao executivo, de um amplo leque de competências e atribuições formais, em domínios que vão desde o ordenamento do território e do urbanismo até a educação, a cultura e o desporto, passando pela saúde, pelo saneamento básico, pela acção social e protecção civil, o Estado, libertando-se de uma boa parte daquelas tarefas logísticas e operacionais, geradoras de encargos, manteve na sua mão a exclusividade dos poderes de concepção, avaliação, financiamento e fiscalização.

Em matéria de política educativa, por meio de uma descentralização mitigada e incompleta, o desequilíbrio de poderes plasmado na Lei de Bases do Sistema Educativo (LBSE) foi sempre mantido com alguma conflitualidade, embora as câmaras municipais se tivessem revelado como protagonistas apropriados para a execução de políticas orientadas pelos princípios da especialização, da diferenciação e da subsidiariedade, ou seja, políticas de proximidade e de apoio especializado aos mais carenciados, aos mais isolados, aos que tinham necessidades educativas especiais, aos que tinham saído precocemente do sistema, aos que queriam ter uma segunda oportunidade. No entanto, era o Estado que continuava a definir o tempo e o modo daquela diferenciação.

Entre elogios à capacidade de iniciativa dos municípios e o seu afastamento intencional das questões educativas principais, entre a imposição avulsa de responsabilidades acrescidas e a recusa do correspondente apoio financeiro, a relação do Estado com os municípios em matéria educativa foi, assim, marcada por um jogo político de sedução e desconfiança, mas sempre com a subordinação do poder local ao poder central e a subalternização das políticas municipais face às políticas governamentais.

Foi sobretudo a partir dos finais da década de 90 que surgiram os sinais de que algo estava a mudar nesta relação de forças: o surgimento de medidas ligadas à expansão da educação pré-escolar, à territorialização 
associativa de projectos educativos, à organização de redes escolares locais e à contratualização de parcerias, com a visibilidade pública das novas dinâmicas de desenvolvimento local, promovidas e geridas pelos municípios. $\mathrm{O}$ traço que emergiu desta fase do processo descentralizador é a consideração do município como um participante público na promoção e coordenação local da política educativa. Esse traço chega aos dias de hoje como um sinal da responsabilização política crescente dos municípios pelo bem comum educativo local.

\section{O OBJECTO DA REFLEXÃO - O MANUAL DE GESTÃO DA EDUCAÇÃO DE ALGUNS MUNICÍPIOS NO CONTEXTO DA DESCENTRALIZAÇÃO}

De facto, na última década e meia, também como efeito de dinâmicas locais (escolares, autárquicas, associativas, etc.) e de sucessivas medidas visando à subsidiariedade e à territorialização educativas, ${ }^{4} \mathrm{o}$ ritmo de transferência de competências da administração central para a local acentuou-se culminando, em 2008, no estabelecimento de "contratos de execução" entre o Ministério da Educação e várias câmaras municipais. ${ }^{5}$ Pela primeira vez, contrariando uma longa história de sucessivas recriminações e desconfianças mútuas, eram anunciados os poderes e os meios financeiros a transferir por meio de negociação directa de um contrato entre o ME e cada um dos municípios interessados.

Se, dez anos atrás, a territorialização educativa havia introduzido algumas mudanças significativas na tradição centralista estatal (FERNANDES, 2005), agora, com a contratualização de um conjunto limitado, mas importante, de competências, assiste-se a um novo e sui generis modelo de transferência de responsabilidades, a que não são alheias as preocupações governamentais de recentralização e de regulação de um sistema cada vez mais dependente de contextos e lógicas de acção locais e, por isso, cada vez mais "centrífugo" e "autónomo".

Argumentando politicamente com a "resolução dos problemas e a redução das assimetrias que subsistem na prestação do serviço educativo" (Decreto-Lei 144/2008) e com base numa matriz pré-definida, o governo ${ }^{6}$ propunhase negociar com cada um dos municípios as competências que a mucipalidade considerava importantes.

Que matérias estavam em causa nos referidos contratos de execução? Tendo em conta que uma parte das competências reguladas pelos contratos já pertencia às escolas ou era detida pela administração central desconcentrada (contratação e gestão de carreiras do pessoal não docente da educação pré-escolar e básica, gestão do apoio socioeducativo durante a escolaridade obrigatória, implementação das actividades de enriquecimento curricular no $1^{\circ}$ ciclo, gestão do parque escolar dos $2^{-}$e $3^{\circ}$ ciclos e transportes escolares), as questões negociais diziam respeito a uma nova repartição de poder entre administração central, escolas e municípios e, por consequência, a uma nova repartição dos meios técnicos, organizacionais e financeiros necessários ao cumprimento dos objectivos propostos em cada contrato. ${ }^{7}$

Como era de esperar, e sem deixar de produzir controvérsia política relacionada com a natureza governamental da medida, esta forma cautelosa de descentralização de poderes e recursos educativos encontrou, por parte dos municípios, respostas muito diversas e algumas dificuldades na sua implementação. Se as primeiras tinham sobretudo a ver com a existência, ou não, de um alinhamento político-partidário dos municípios com o governo, as segundas diziam respeito à capacidade negocial e às condições de contexto que os municípios apresentavam. Isso porque muitos não só não dispunham de um sistema de gestão da educação que respondesse às novas exigências regulamentares, mas, sobretudo, porque careciam das competências organizacionais e de planeamento que lhes permitissem levar a cabo intervenções estratégicas novas, de elevada exigência técnica e sob forte escrutínio social e político.

Passados quatro anos desde a implementação dos contratos, está ainda por fazer uma avaliação pluridimensional, caso a caso, da medida descentralizadora e um balanço das respectivas consequências aos diversos níveis.

Decorrem, no entanto, algumas iniciativas municipais ou de instituições que juntam câmaras e universidades que, não tendo a avaliação como objectivo, podem não só contribuir para a compreensão do modo como o processo vem se desenvolvendo no terreno, mas também para o desenho de um projecto avaliativo, na medida em que já identificam indicadores e produzem dados muito significativos sobre o processo em curso.

Este é, em parte, o caso da Comunidade Intermunicipal do Cávado (CIM) constituída pelos municípios de Amares, Barcelos, Braga, Esposende, Terras de Bouro e Vila Verde.

Face aos desafios colocados pelo avanço da descentralização, e embora apenas três tivessem subscrito os contratos de execução, os municípios que integram a CIM Cávado, com o apoio da Universidade do Minho, ${ }^{8}$ desenvolveram, entre 2010 e 2012, um projecto de formação-acção transversal, Projecto EduCávado, com o objectivo de (re)estruturação da função educação e de, assim, qualificarem o seu papel de regulador e de coconstrutor das políticas educativas locais.

De entre os vários produtos resultantes do projecto, que vão desde o diagnóstico de necessidades até a formação de técnicos e responsáveis intermédios, destaca-se a elaboração, por parte de cada um daqueles 
municípios, de um Manual de Gestão Educativa, que pretende constituir-se como o documento estruturante, estratégico e processual daquela (re)estruturação, ou seja, como a fundamentação de um novo Plano Municipal de Educação.

Este texto é uma primeira reflexão sobre esses manuais. O objecto específico de reflexão é constituído pelas escolhas feitas por cada um dos seis municípios sobre a importância estratégica e os objectivos dos processos de gestão educacional, tendo em conta o novo contexto descentralizador.

Embora obedeçam a uma arquitectura comum, composta por quatro capítulos - i) Enquadramento da função educação, ii) Organograma e principais responsabilidades, iii) Identificação dos principais processos e iv) Modelo de monitorização e respectivos indicadores -, os manuais resultam de contextos, de opções políticas, de lógicas de acção ${ }^{9}$ e de experiência acumulada muito diferentes, o que os leva a propor não só modos específicos de apropriação das orientações nacionais definidas, mas sobretudo diferentes prioridades e justificações na sua estratégia educacional.

Ora, em investigações anteriores que efectuámos sobre os diferentes tipos de acção educativa municipal, ${ }^{10}$ tentámos demonstrar que as decisões municipais passam, em graus variáveis, pela reinterpretação de competências formais, pela contestação aberta ou pela acomodação às orientações nacionais, pela maior ou menor transgressão de regras estabelecidas, pela mobilização de meios e recursos locais, pela imposição de soluções ou pela sua negociação com parceiros e pelo favorecimento de umas lógicas contra outras, etc. (MARTINS, 2007). Sendo assim, apesar de toda a ambiguidade que fomos sublinhando a propósito do modelo descentralizador das últimas décadas, constatámos que a maioria dos municípios rejeita intervenções directas nos domínios nucleares da gestão das escolas, do recrutamento e avaliação de professores directamente responsáveis pelas áreas curriculares, do controlo do rendimento escolar dos alunos e da avaliação das escolas.

Essas conclusões constituem nosso referencial teórico de análise, reforçado pelo entendimento de que, embora estes domínios de intervenção estejam previstos em diversas regulamentações, caso dos conselhos de escola, dos contratos de autonomia e dos conselhos municipais de educação, eles não são abertamente assumidos porque, "por um lado, existe o receio de que essa interferência se transforme, na prática, em novas competências, não regulamentadas, sem a correspondente transferência de verbas para a sua execução.” E, por outro lado, porque, "continuando o sistema educativo a ser, no essencial, regulado pela administração central ou desconcentrada, os municípios têm receio de ficarem com os problemas, sem disporem de meios necessários à sua solução" (PINHAL, 2004, p. 126).

Por isso, os manuais permitem antecipar o sentido das mudanças nas práticas municipais por eles modeladas no desenvolvimento da função educativa.

Assim, este texto pretende identificar não apenas as diferentes prioridades de acção de cada município e as respectivas justificações, mas também o modo como priorizam os vários processos que integram a administração educativa local e o modelo de municipalismo educativo que lhes subjaz, no quadro da problemática que apresentámos no ponto anterior. A identificação dessas prioridades permitir-nos-á, por fim, reflectir sobre o grau de (des)articulação estabelecida entre as agendas educativas nacional e local e as consequências que daí advêm para a regulação global do sistema.

Para entender a importância da articulação entre prioridades nacionais e locais, importa recordar que os domínios propostos e financiados pelo ME nos contratos eram:

i) Pessoal não docente das escolas básicas e da educação pré-escolar;

ii) Componente de apoio à família, designadamente o fornecimento de refeições e apoio ao prolongamento de horário na educação pré-escolar;

iii) Actividades de enriquecimento curricular no $1^{\mathrm{o}}$ ciclo do ensino básico;

iv) Gestão do parque escolar nos $2^{\circ}$ e $3^{\circ}$ ciclos do ensino básico;

v) Acção social escolar dos $2^{\circ}$ e $3^{\circ}$ ciclos do ensino básico;

vi) Transportes escolares relativos ao $3^{\mathrm{O}}$ ciclo do ensino básico.

A transferência real das atribuições e competências das alíneas i), iii) e iv) dependia da existência da carta educativa ${ }^{11}$ e da celebração de contratos de execução por cada um dos municípios (Decreto-Lei 144/2008).

\section{A anÁlise - OS MANUAis de GeSTÃo DA EDUCAÇÃO DOS MUNIĆ́PIOS DA COMUNIDADE INTERMUNICIPAL do Cávado}

\section{Enquadramento da função educação}

Este primeiro capítulo dos manuais pode ser globalmente considerado como o espaço privilegiado pelos seus autores (responsáveis autárquicos aos diversos níveis) para a explicitação de justificações e motivos das opções feitas no passado recente, mas também para a "apresentação" de fontes de legitimação para o que cada município pretende fazer no futuro próximo.

O Quadro 1 resume as referências mais significativas daquilo que cada município entendeu explicitar como "enquadramento da função educação". 
Quadro 1 - Justificações do "enquadramento da função educação" por município

\begin{tabular}{|c|}
\hline Amares \\
\hline A educação é apresentada como domínio \\
prioritário e de grande importância política. \\
Releva a experiência já acumulada nos domí- \\
nios tradicionais: construção, apetrechamento e \\
manutenção dos estabelecimentos de educação \\
pré-escolar e das escolas do 1º ciclo, organização \\
e gestão dos transportes escolares, apoio ao \\
desenvolvimento de actividades complementares \\
de acção educativa na educação pré-escolar e no \\
1o ciclo. \\
Tem Carta Educativa desde 2007. \\
Celebrou, em março de 2009, o Contrato de \\
Execução.
\end{tabular}
Execução.

Considera-se um espaço que articula a educação escolar com os outros modos de educação ao longo da vida.

Considera-se um contexto favorável ao desenvolvimento de relações sociais de parceria e de codefinição e concretização de políticas educativas locais.

Descreve as medidas tomadas nos últimos anos, quer as que são rotinas quer as que são inovadoras e específicas. Enfatiza a reorganização da rede de educação pré-escolar e do $1^{\mathrm{O}}$ ciclo, com a entrada em funcionamento de seis novos centros escolares e o encerramento de todas as escolas.

Manifesta a vontade de construção de um Projecto Educativo Municipal.

\begin{tabular}{|l|l}
\hline Barcelos & Braga
\end{tabular}

Refere a existência de uma política municipal de desenvolvimento estratégico e sustentado que perspectiva a escola como o espaço "de excelência da acção educativa".

Não celebrou Contrato de Execução.

Valoriza o facto de se estar a implementar a Proposta de Alteração da Carta Educativa, que vai reordenar e requalificar toda a rede do pré-escolar e do $1^{\mathrm{O}}$ ciclo, por meio de um conjunto de 19 novos centros escolares.

Valoriza o estabelecimento de parcerias numa perspectiva de promoção de educação ao longo da vida, de diversificação das oportunidades de formação qualificante e de satisfação das necessidades empresariais.

Descreve as medidas tomadas nos últimos anos, quer as que são rotinas quer as que são inovadoras e específicas.

Refere a importância da participação dos responsáveis autárquicos nas reuniões dos conselhos gerais das escolas.

Manifesta a vontade de transformar o município numa verdadeira cidade educadora.
O enquadramento chama a atenção para a descrição anexa do "Perfil sócio-organizacional dos agrupamentos escolares e escolas não agrupadas" do município.

Refere que a educação "tem sido e continuará a ser uma prioridade", razão pela qual dará continuidade aos objectivos da Carta Educativa.

Para além do desenvolvimento dos projectos educativos camarários em curso, pretende intensificar a relação entre a autarquia e os agrupamentos de escolas "divulgando e valorizando os bons projectos educativos".

Acentua a necessidade de adaptação das políticas educativas nacionais à realidade municipal.

Celebrou o Contrato de Execução em janeiro de 2009 e destaca as novas competências daí de correntes: pessoal não docente do pré-escolar e básico, actividades de enriquecimento curricular no $1^{\mathrm{o}}$ ciclo, gestão do parque escolar dos $2^{\mathrm{o}}$ e $3^{\mathrm{o}}$ ciclos do básico. Esta última competência é acolhida na Carta Educativa Municipal.

Descreve as medidas tomadas nos últimos anos, quer as que são rotinas quer as que são inovadoras e específicas.

Esposende

São apresentados os objectivos estratégicos do município em matéria de educação, nomeadamente o cumprimento das atribuições educativas formais, a intervenção integrada, enquadrada e fundamentada nos princípios da Carta das Cidades Educadoras (de cuja associação faz parte), o contributo para uma educação de qualidade para todos (no acesso e na permanência dos jovens na escola), na igualdade de oportunidades, na promoção de um planeamento integrado potenciando sinergias, competências e recursos locais, articulando políticas que implementem a qualidade de vida dos cidadãos, a cidadania e a democracia participativa e solidária, lutando pelos objectivos e metas estabelecidos pelo SIGQA.

Embora tal não seja referido, não celebrou o Contrato de Execução.

Descreve as funções que cabem ao Serviço de Educação nos domínios da acção social escolar, do Conselho Municipal de Educação, da CAF do pré-escolar, do programa de generalização do serviço de refeições, da gestão e acompanhamento do pessoal não docente da educação pré-escolar, do desenvolvimento de programas de orientação vocacional e profissional, de actividades de avaliação psicológica, de implementação do Programa de Actividades de Enriquecimento Curricular e de gestão do parque escolar.

Descreve as medidas tomadas nos últimos anos, quer as que são rotinas quer as que são inovadoras e específicas.

Descreve e valoriza os objectivos mais gerais dos serviços municipais e a sua articulação interna e externa.

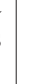

-


De uma forma mais ou menos explícita, todos reafirmam a importância estratégica que a educação assume no desenvolvimento do município.

No entanto, há nuanças no entendimento dessa importância. Por exemplo, enquanto que no caso de Vila Verde é sublinhada a necessidade de "modernizar a educação" e de esta modernização estar, sobretudo, ao serviço do desenvolvimento social e económico ("o investimento numa educação moderna e impulsionadora de desenvolvimento, como dimensão estruturante do progresso"), devendo ser acolhida no planeamento estratégico para os próximos três anos, no caso de Amares a prioridade concedida à educação tem a ver com a possibilidade da institucionalização de um (explicitamente não existente) Projecto Educativo Municipal que traduza o "desenvolvimento de relações sociais de parceria e de codefinição e concretização de políticas educativas locais". Ou seja, enquanto no primeiro caso a educação parece ser considerada numa perspectiva praxiológica, mais preocupada com a economia e o desenvolvimento local, no segundo caso ela surge mais ligada à ontologia, à construção da cidadania individual e à ideia da qualificação do contexto social dos munícipes.

Esses dois posicionamentos colocam a questão de fundo da justificação da acção (BOLTANSKI; THÉVENOT, 2006). Esta questão, que existe em todos os municípios, mas que não é respondida da mesma forma por todos, consiste na capacidade de cada município definir, ou não, o papel estratégico que cabe à educação local por contraste com as finalidades, supostamente universalizadas e aceites, da educação nacional.

Uma boa parte dos municípios resolve o problema assumindo-se como Município Educador ${ }^{12}$ (casos de Barcelos, Braga e Esposende) ou manifestando a vontade de aderir aos princípios da respectiva Carta de Princípios (caso de Vila Verde), enquanto outra afirma a vontade (como possibilidade prática) de desenvolver um Projecto Educativo Municipal próprio, complementar e "autónomo" face às finalidades da educação nacional (Amares). O sexto afirma apenas a sua vontade estratégica de se reestruturar e qualificar internamente como parceiro das escolas (Terras de Bouro).

A partir desses posicionamentos, constata-se que o conceito de política educativa local não é uniformemente entendido (no seu âmbito e alcance) nem aceite pelos municípios, embora todos considerem que devem cumprir as atribuições e competências educativas formais, o que por si só não equivaleria a desenvolver uma política local.

De facto, alguns consideram que a educação é um assunto reservado das escolas, dos pais e do ministério, pouco havendo a fazer por parte das autarquias. Este posicionamento defensivo condiciona a natureza política do que está em questão, ou seja, da problemática da descen- tralização e dos modos como esta se processa. Por isso, valorizam a política municipal de desenvolvimento estratégico e sustentado que perspectiva a escola como o espaço "de excelência da acção educativa" (Barcelos), afastando assim a escola (a sua eficácia e a sua eficiência) do raio de acção municipal. Um pouco como corolário dessa linha de pensamento, nenhum dos seis municípios faz qualquer referência concreta ao desempenho do seu sistema educativo formal, ao rendimento escolar das suas crianças e jovens, à boa ou insuficiente diversificação das ofertas formativas ou à organização e funcionamento de escolas e agrupamentos, nomeadamente à participação dos representantes autárquicos nos órgãos de gestão escolares. Apenas um dos municípios, no enquadramento da função educação, refere que, para além do desenvolvimento dos projectos educativos camarários em curso, pretende intensificar a relação entre a autarquia e os agrupamentos de escolas "divulgando e valorizando os bons projectos educativos" (Braga).

Por outro lado, todos referem a existência de Carta Educativa Municipal, mas se para alguns ela parece estar a impulsionar uma nova oportunidade de planeamento educativo, mais ambicioso, por força da sua revisão (Barcelos valoriza o facto de se estar a implementar a Proposta de Alteração da Carta Educativa, que vai reordenar e requalificar toda a rede do pré-escolar e do $1^{\circ}$ ciclo, por meio de um conjunto de 19 novos centros escolares; Vila Verde valoriza a Carta Educativa, na perspectiva do investimento feito em centros escolares "potenciadores da elevação e homogeneização da qualidade da educação proporcionada a todas as crianças"), em nenhum dos seis municípios esse tema abriu a oportunidade de discussão sobre a reorganização dos agrupamentos e suas consequências. Aliás, apenas Braga descreve com minúcia, como anexo ao capítulo do enquadramento, o "Perfil sócio-organizacional dos agrupamentos escolares e escolas não agrupadas" do município.

Pelo contrário, no que diz respeito à caracterização interna dos serviços técnicos e administrativos responsáveis pela administração educativa local, todos os municípios a enfatizam no respectivo enquadramento, nomeadamente aos níveis da articulação horizontal e vertical com os outros serviços e da integração nos novos sistemas de gestão da qualidade (Esposende luta pelos objectivos e metas estabelecidos pelo SIGQA; Terras de Bouro quer garantir que a Divisão de Educação, a criar, alcance uma perspectiva transversal).

Também todos os seis municípios referem exaustivamente as "medidas tomadas nos últimos anos, quer as que são rotinas quer as que são inovadoras e específicas". Ora, é justamente sobre estas últimas, geralmente muito justificadas, que se fundamenta a existência da política educativa local, mesmo quando ela não é explicitamente assumida pelos seus autores. 
Tendo em conta as escolhas vertidas para o capítulo de enquadramento da função educação e tendo em conta, também, que dos seis, só três municípios (Amares, Braga e Terras de Bouro) tomaram a decisão de celebrar contrato de execução, sendo que, à data, destes, só Braga era da mesma cor política do governo, somos levados a concluir que são as decisões tomadas sobre medidas inovadoras e o modo como é feita essa execução, ou como são decididas determinadas opções e prioridades, que estão para lá das atribuições formais, que determinam a "autoconsciencialização" da existência de uma política educativa municipal.

\section{Identificação dos principais processos}

Como já referimos, é no Capítulo III dos manuais que os municípios descrevem com minucia técnica cada um dos processos que escolheram como prioritários no domínio da educação.

Como refere um dos municípios (Vila Verde), devese entender por processo o "conjunto de atividades interrelacionadas e interatuantes que transformam entradas em saídas". As entradas correspondem às demandas das partes interessadas, ou seja, das pessoas ou grupos com interesse no desempenho ou sucesso da organização administrativa local. Assim, as demandas são objecto de "procedimentos" ou "modos especificados de realizar uma atividade ou um processo", nos termos e respeito pela legislação em vigor, tendo em vista a produção dos efeitos pretendidos - as saídas.

A descrição de cada processo deve incluir os documentos, métodos e registos que lhe estão associados, em conformidade com requisitos específicos, incluindo limitações de tempo, custos e recursos. Mas a sua característica fundamental é a descrição dos objectivos que justificam quer a sua existência, quer a demanda que foi feita pelo munícipe. Por isso eles são estruturantes da actividade educativa municipal. Aliás, é com base na descrição desses objectivos que pode ser realizado o acompanhamento, a monitorização e a avaliação do processo, nomeadamente através dos indicadores de desempenho que decorrem daqueles objectivos.

O Quadro 2 é justamente o resumo dos processos escolhidos por cada uma das seis câmaras, considerando apenas a designação ${ }^{13}$ de cada processo e os correspondentes objectivos. Embora fosse interessante abarcar as outras dimensões que lhes são próprias, é apenas sobre estes dois aspectos que nos iremos debruçar por forma a dele retirarmos algumas conclusões finais.

É um facto a variabilidade no número de processos estruturantes: Esposende, com 3; Barcelos e Vila Verde, com 5; Braga e Terras de Bouro com 6; Amares com 7. Se essa variabilidade indicia tipos de organização e funcionamento consentâneos (através da intervenção de estruturas internas mais amplas ou mais diferenciadas), o elenco dos processos dá-nos pistas sobre o que cada município considera mais importante.

Desse ponto de vista, ressalta o facto de todos terem em comum três processos: Acção Social Escolar, Parque Escolar e Programas ou Planos de Iniciativas Educativas. No primeiro e no segundo estão em jogo atribuições e competências antigas, nas quais os municípios já detêm uma larga experiência de planeamento, execução e controlo. Apesar disso, as diferenças, no primeiro, revelamse nos "pormenores" que demonstram especial empenho em resolver problemas locais e/ou inovar através novas abordagens. São os casos dos processos constituídos em torno dos transportes escolares, dos transportes especiais, das refeições escolares, da fruta escolar e dos auxílios económicos. No segundo, nem sequer se nota essa diferença: todos baseiam o processo de Parque Escolar no objectivo da melhoria dos equipamentos já existentes e na reorganização das redes de oferta de pré-escolar e do $1^{\mathrm{O}}$ ciclo, através de novos centros escolares.

É no terceiro processo que se manifestam, eventualmente, as intervenções que estão para lá das tradicionais competências, na medida em que representam a capacidade de intervenção estratégicas dos municípios. Sob a designação genérica de Programas ou Planos de Iniciativas Educativas, é aqui que surgem as propostas de realização de atividades e projectos adequados às necessidades dos alunos e das escolas (note-se que este era um domínio tradicionalmente vedado às autarquias), que configuram verdadeiros planos municipais de educação.

Em alguns casos, este planeamento estratégico já aponta para a necessidade de formulação de um Projecto Educativo Municipal, mas, curiosamente, no maior dos seis (Braga) tal não acontece, optando este município pelo elencar de projectos sectoriais (fruta escolar, quinta pedagógica, escola de educação rodoviária) e por um investimento muito forte nas Actividades de Enriquecimento Curricular. Esses, ao contrário da importância que lhes é atribuída a nível nacional, apenas são objecto de processos estruturantes nos municípios de Amares e Terras de Bouro, sendo que em Vila Verde nem sequer são assumidas pela câmara.

\section{CONSIDERAÇÕES FINAIS}

Podemos concluir então que a agenda educativa municipal actual é ainda muito influenciada pela agenda nacional e pelas propostas que o governo apresentou aos municípios em 2008, por meio dos contratos de execução. Estes, embora não tenham sido aceites por todas as câmaras, acabaram por influenciar o municipalismo educativo, cumprindo assim o seu primordial papel regulador e recentralizador. 
Quadro 2 - Identificação dos principais processos de administração educacional por município

\begin{tabular}{|c|c|c|}
\hline Município & Processo & Objectivos \\
\hline \multirow{7}{*}{ Amares } & 1. Transportes Escolares & Definir a forma de requerer o passe de transporte escolar em carreira pública. \\
\hline & 2. Iniciativas Educativas & Realização de atividades adequadas às necessidades dos alunos. \\
\hline & 3. Refeições Escolares & Serviço de alimentação adequado às necessidades da comunidade educativa. \\
\hline & 4. Acção Social Escolar & Serviço de alimentação adequado às necessidades da comunidade educativa. \\
\hline & 5. Parque Escolar & Parque escolar adequado às necessidades dos alunos \\
\hline & 6. AEC & Selecção de professores AEC com perfis adequados às necessidades. \\
\hline & 7. Pessoal Não Docente & Seleção e gestão adequada de pessoal não docente com perfis adequados às necessidades das crianças. \\
\hline \multirow{5}{*}{ Barcelos } & 1. Transportes & $\begin{array}{l}\text { Disponibilização do adequado serviço de transporte entre o local de residência e os estabelecimentos } \\
\text { de ensino para todos os alunos do ensino básico e secundário, oficial ou particular e cooperativo (com } \\
\text { contrato de associação e paralelismo pedagógico de ensino). Gradual alargamento da gratuitidade do } \\
\text { passe escolar para os alunos do ensino secundário. }\end{array}$ \\
\hline & 2. Refeições Escolares & $\begin{array}{l}\text { Fornecimento da alimentação aos alunos que frequentam os JI e as escolas do } 1^{\circ} \text { ciclo, com a garantia } \\
\text { da qualidade da alimentação fornecida - quantidade, segurança e higiene alimentares -, bem como com } \\
\text { a qualidade nutricional da mesma. }\end{array}$ \\
\hline & 3. PND & $\begin{array}{l}\text { Proceder à gestão administrativa e previsional dos recursos humanos (mapa de pessoal, gestão cadastral, } \\
\text { processamento de remunerações e abonos). }\end{array}$ \\
\hline & 4. Parque Escolar & $\begin{array}{l}\text { Elaborar os programas funcionais dos edifícios escolares e acompanhar e apoiar, através de pareceres } \\
\text { técnicos, as ações de construção, reparação ou manutenção do parque escolar. }\end{array}$ \\
\hline & 5. P. A. Educativas & $\begin{array}{l}\text { Atividades destinadas às escolas organizadas pela câmara: Cultura (Biblioteca, Arquivo Municipal, } \\
\text { Museu de Olaria, Gabinete de Arqueologia, Artes e Associações Culturais), Educação, Ambiente, } \\
\text { Proteção Civil, Comissão de Proteção a Crianças e Jovens, Turismo, Juventude, etc. Apoio a Projetos } \\
\text { Educativos das Escolas. } \\
\text { Este apoio, para além do } 1^{\circ} \text { ciclo, estende-se aos } 2^{\circ}, 3^{\circ} \text { ciclos e secundário e pode verificar-se através de } \\
\text { apoio financeiro, logístico ou técnico. }\end{array}$ \\
\hline \multirow{7}{*}{ Braga } & 1. Auxílios Económicos & $\begin{array}{l}\text { Apoios socioeducativos: refeição e prolongamento de horário para alunos do } 1^{\circ} \text { ciclo e manuais escolares/ } \\
\text { material didáctico. }\end{array}$ \\
\hline & 2. Fruta Escolar & $\begin{array}{l}\text { Distribuição gratuita de hortofrutícolas aos alunos do } 1^{\circ} \text { ciclo para o incremento destes géneros } \\
\text { alimentícios entre os mais novos, promovendo uma alimentação saudável e a prevenção da obesidade } \\
\text { infantil. }\end{array}$ \\
\hline & 3. Transportes Especiais & $\begin{array}{l}\text { Planeamento que permita conjugar as áreas de influência pedagógica das escolas do concelho com os } \\
\text { transportes públicos e com circuitos particulares. }\end{array}$ \\
\hline & 4. $\mathrm{AEC}$ & $\begin{array}{l}\text { Alargar o leque das ofertas de ensino a outras atividades, para além do Inglês, tais como AFD, Música, } \\
\text { Expressão Musical, TIC, Expressão Dramática, Estudo do Meio/Ciências Experimentais. Elaborar um } \\
\text { manual de acolhimento para os professores de AEC. }\end{array}$ \\
\hline & 5. Pessoal Não Docente & $\begin{array}{l}\text { Assegurar a colocação de trabalhadores nos agrupamentos de escolas, pedidos de mudança entre } \\
\text { agrupamentos, controlo dos mapas mensais de assiduidade remetidos pelos agrupamentos, pedidos de } \\
\text { verificação de doenças e de juntas médicas, processamento de vencimentos, apresentação de candidaturas } \\
\text { ao IEFP, entre outros. }\end{array}$ \\
\hline & 6. Parque Escolar & $\begin{array}{l}\text { Dotar o parque escolar com condições para as exigências educativas, nomeadamente as que se reportam às } \\
\text { disciplinas curriculares e enriquecimento curricular, bem como às de animação e ao apoio socioeducativo } \\
\text { dos alunos, recente construção dos novos centros escolares. }\end{array}$ \\
\hline & 7. CAF & Oferta dos apoios socioeducativos - refeição e prolongamento de horário nos JI. \\
\hline \multirow{3}{*}{ Esposende } & 1. Acção Socioeducativa & $\begin{array}{l}\text { Promover a qualidade ao nível das refeições escolares. Promover a aferição do grau de satisfação dos } \\
\text { beneficiários de bolsas de estudo. }\end{array}$ \\
\hline & 2. Apetr. do Parque Escol. & Promover a gestão eficaz do parque escolar. \\
\hline & 3. Programas Educativos & Assegurar as actividades previstas no início do ano lectivo a todos os alunos. \\
\hline \multirow{6}{*}{ Terras de Bouro } & 1. Plan. Iniciativas Educ. & Realização de atividades adequadas às necessidades dos alunos. \\
\hline & 2. Transportes Escolares & $\begin{array}{l}\text { Gestão adequada da rede de transporte escolar. Transporte escolar disponível nos horários convenientes } \\
\text { a alunos e parceiros. }\end{array}$ \\
\hline & 3. Acção Social Escolar & $\begin{array}{l}\text { Assegurar apoio a famílias carenciadas, contribuindo para que todos possam usufruir de uma educação } \\
\text { de qualidade. }\end{array}$ \\
\hline & 4. Parque Escolar & Parque escolar adequado às necessidades dos alunos. \\
\hline & 5. AEC & Seleção de professores AEC com perfis adequados às necessidades. \\
\hline & 6. Pessoal Não Docente & Seleção e gestão adequada de pessoal não docente com perfis adequados às necessidades das crianças \\
\hline \multirow{5}{*}{ Vila Verde } & 1. P. Educativo Municipal & $\begin{array}{l}\text { Implementar projectos de acordo com as necessidades diagnosticadas. Promover e assegurar condições } \\
\text { para as práticas ajustadas às exigências de uma educação de qualidade. }\end{array}$ \\
\hline & 2. Transportes Escolares & $\begin{array}{l}\text { Melhoria na gestão dos transportes escolares. Garantir maior celeridade na fixação dos circuitos esco- } \\
\text { lares. Garantir que os agrupamentos cumpram os prazos de comunicação das necessidades de transporte. }\end{array}$ \\
\hline & 3. Acção Social Escolar & Melhoria na implementação da ação social escolar (manuais escolares e refeições). \\
\hline & 4. Comp. Apoio Família & Melhoria na implementação da CAF (educação pré-escolar). \\
\hline & 5. Parque Escolar & Melhoria na gestão do parque escolar. \\
\hline
\end{tabular}


No entanto, face ao conjunto dos principais processos de administração da educação, onde são relevantes as questões da gestão de pessoal não docente, do reordenamento e requalificação da rede de escolas do préescolar e do $1^{\mathrm{O}}$ ciclo, da oferta de serviços socioeducativos e da administração da acção social escolar, podemos admitir que a lógica de acção educativa destes municípios pode variar entre o "modelo de uma dissociação mitigada" comandado pela forte conjugação da informalidade com a lógica de mercado e um "modelo de autonomia", que, embora também reinterprete as orientações nacionais à luz dos seus contextos próprios, aparece mais comprometido com a mobilização social de parceiros e recursos educativos locais.

\section{REFERÊNCIAS}

BARROSO, João; PINHAL, João (Org.). A administração da educação: os caminhos da descentralização. Lisboa: Colibri, 1996.

BARROSO, João (Org.) et al. A Regulação das Políticas Públicas de Educação. Espaços, Dinâmicas e Actores. Lisboa: Educa, 2006.

BDJUR, Base de Dados Jurídica. Constituição da República Portuguesa. Coimbra: Almedina, 2010.

BOLTANSKI, Luc; THÉVENOT, Laurent. On justification: the economies of worth. Princeton: Princeton University Press, 2006.

FERNANDES, António Sousa. Educação e poder local. In: CONSELHO NACIONAL DE EDUCAÇÃO. Educação, comunidade e poder local. Braga: Universidade do Minho, 1994. p. 159-180.

FERNANDES, António Sousa. Município, cidade e territorialização educativa. In: COSTA, Jorge Adelino; NETOMENDES, António; VENTURA, Alexandre (Org.). Políticas e gestão local da educação. Aveiro: Universidade de Aveiro, 2005. p. 35-43.

MARTINS, Jorge. O papel dos municípios na construção das políticas educativas. (Tese de doutoramento). Porto: Faculdade de Psicologia e de Ciências da Educação/UP, 2007.

PINHAL, João. Os municípios e a provisão pública de educação. In: COSTA, Jorge Adelino; NETO-MENDES, António; VENTURA, Alexandre (Org.). Políticas e gestão local da educação. Aveiro: Universidade de Aveiro, 2004. p. 45-60.

SARMENTO, Manuel. Lógicas de acção nas escolas. Lisboa: IIE/ME, 2000.

\section{Notas}

1 Das autarquias locais previstas pela CRP, apenas existem freguesias (unidades de administração territorial mais próximas do cidadão) e municípios (que agregam um número variável de freguesias, constituindo um segundo nível da administração pública), sendo que as regiões administrativas nunca foram implementadas. Antes do recente processo de reorganização administrativa do país, que levou à fusão de várias freguesias, Portugal tinha 4259 freguesias distribuídas por 308 municípios.
2 Umas mais orientadas por políticas de desenvolvimento baseado em obras públicas e construção de equipamentos sociais, outras mais focadas na elevação dos níveis de escolarização, formação profissional e educação de adultos dos munícipes.

3 É na década de 1980 que são publicados os principais normativos da descentralização educativa: Decreto-Lei 77/84, de 8 de março (definição das competências municipais em relação a investimentos público); Decreto-Lei 98/84 (alterações à Lei das Finanças Locais); DecretoLei 100/84, de 29 de março (Lei das Autarquias Locais); Decreto-Lei 299/84, de 5 de setembro (Organização, financiamento e controlo de funcionamento dos transportes escolares); Decreto-Lei 399-A/84, de 28 de dezembro (Transferência de competências para os municípios em matéria de acção social); Lei 46/86, de 14 de outubro (Lei de Bases do Sistema Educativo - LBSE).

4 Teorizada e implementada no âmbito do Pacto Educativo para o Futuro, documento aprovado pelo XIII Governo Constitucional.

5 Pelo Decreto-Lei 144/2008, de 28 de julho (Transferência de Competências e respectivos Contratos de Execução) tinham sido assinados, até fevereiro de 2010, 113 contratos de execução, ou seja, 41\%, dos 278 municípios do continente, estando ainda por publicar nessa data um contrato. Tal significa que se encontravam ainda 164 municípios (59\%) sem contrato (OPLE, 2010).

6 XVII Governo Constitucional, de maioria absoluta PS

7 Cada contrato de execução, contendo cláusulas obrigatórias relativas à transferência dos recursos humanos, patrimoniais e financeiros associados ao desempenho das competências previstas, aos direitos e obrigações das partes contratantes e à definição dos instrumentos financeiros utilizáveis, pressupunha o seu próprio acompanhamento e controlo da execução por meio da constituição de uma comissão de acompanhamento tripartida, composta por um representante do ME, um representante da Câmara Municipal e um representante do conjunto dos agrupamentos de escolas do concelho.

8 Por meio da empresa TecMinho, responsável pela implementação do projecto.

9 O conceito de lógica de acção é aqui usado como sendo o conjunto de racionalidades dos actores que orientam e dão sentido (subjectivo e objectivo) às suas escolhas e às suas práticas, no contexto de uma acção (SARMENTO, 2000; BARROSO et al., 2006).

${ }^{10}$ MARTINS, 2007). O papel dos municípios na construção das políticas educativas. (Tese de doutoramento). Porto: Faculdade de Psicologia e de Ciências da Educação/UP. Neste estudo foi construída uma tipologia de caracterização da acção educativa municipal com quatro modelos definidos em função de duas grandes variáveis: mobilização de meios e recursos (com extremos opostos na mobilização pelo mercado e na mobilização pela intervenção associativa e social) e a atitude face aos mecanismos de regulação institucional (com extremos opostos na formalidade de aceitação rigorosa e sistemática dos normativos e orientações e na acção informal, autónoma e autorregulada). Os quatro "modelos" foram designados de "modelo de acomodação", "modelo de adesão", "modelo de autonomia" e "modelo de dissociação ou resistência",

11 As Cartas Educativas, instrumentos de planeamento municipal, tinham sido previstas em 2003, num decreto (DL 7/2003, de 15 de janeiro), que também previa a criação dos Conselhos Municipais de Educação, que vieram substituir, sem vantagem, os anteriores Conselhos Locais de Educação, como órgãos de aconselhamento e concertação em matéria educativa local.

12 A Rede Territorial Portuguesa das Cidades Educadoras acolhe atualmente 47 municípios aderentes à AICE. Na CIM Cávado são três: Barcelos, Braga e Esposende.

${ }^{13} \mathrm{Na}$ designação de alguns processos, no Quadro 2, são utilizadas referências abreviadas e siglas, cuja significação é a seguinte: AEC - Actividades de Enriquecimento Curricular; PND - Pessoal Não Docente da educação pré-escolar e do ensino básico e secundário; P. A. Educativas - Plano de Actividades Educativas; CAF - Componente de Apoio à Família no pré-escolar e no $1^{\mathrm{O}}$ ciclo do ensino básico; AFD - Actividade Física e Desportiva, uma das actividades de enriquecimento curricular; IEFP Instituto de Emprego e Formação Profissional; JI - Jardim de Infância; P. Educativo Municipal - Plano Educativo Municipal.

Artigo recebido em março 2014.

Aprovado em junho 2014 
